\title{
COMMENTARY
}

\section{Angiogenesis in the thyroid gland}

\author{
J D Ramsden
}

Department of Medicine, Queen Elizabeth Hospital, Birmingham B15 2TH, UK

\begin{abstract}
Angiogenesis is the mechanism of blood vessel formation after the first few days of embryogenesis, and is essential for all tissue growth. In adults, angiogenesis occurs in the thyroid during disease processes including goitre, Graves' disease, thyroiditis and cancer. The molecular mechanisms controlling angiogenesis are becoming clearer, and therapy targeting these processes is coming closer to clinical fruition. Both promoters and inhibitors of angiogenesis
\end{abstract}

have been identified in the thyroid, including vascular endothelial growth factor (VEGF), fibroblast growth factor, and thrombospondin. This commentary will review the understanding of the control of angiogenesis within the context of the thyroid gland, and review the pre-eminent role of VEGF as the angiogenic signal from the follicular cells to the endothelial cells.

Journal of Endocrinology (2000) 166, 475-480

\section{Introduction}

Angiogenesis is the sprouting of new blood vessels from pre-existing capillaries, and requires the multiplication of endothelial cells, their migration, remodelling of the extracellular matrix, tube formation and recruitment of surrounding structures to maintain the newly formed vessels. Before a functional network is formed, anastomoses must be made with other new or pre-existing vessels, and the basement membrane must be established (Risau 1997). This process is tightly controlled, and occurs rarely in the adult vasculature except for wound healing, the menstrual cycle in the female reproductive tract, and pathological conditions including diabetic retinopathy and tumour formation (Folkman 1995). Tumour formation requires the development of a blood supply to allow growth larger than $2 \mathrm{~mm}$ in diameter, and thus inhibition of angiogenesis could prevent tumour growth and metastasis (Folkman 1971). Very little angiogenesis occurs in normal adult blood vessels, which makes the development of treatments to prevent vessel growth a very promising therapeutic goal. It has been recognised recently that promotion of blood vessel growth can ameliorate the severity of occlusive vascular disease, such as coronary and peripheral ischaemic disease (Henry 1999).

Increased vascularity in the thyroid can occur in hyperplastic goitre, Graves' disease and cancer, and may be associated with a vascular hum because of increased blood flow. In cancers of the thyroid, microvessel density has been shown to correlate with disease-free survival in papillary carcinoma of the thyroid (Ishiwata et al. 1998) and intrathyroid tumour spread in follicular carcinoma (Segal et al. 1996).

In experimental induction of goitre by low iodine and thiouracil in rats, Wollman et al. (1978) showed that the capillaries within the thyroid clearly enlarged within 3 days of treatment, and by 20 days they almost completely surrounded the follicles with a continuous endothelial sheet. There was both fusion of capillaries and mitosis of endothelial cells. There was no change in blood vessel morphology or number in nearby extrathyroidal tissue, including the parathyroids. In this model, endothelial cell proliferation occurs before thyroid epithelial cell growth (Wollman et al. 1978, Denef et al. 1981, Smeds \& Wollman 1983, Many et al. 1984), and Wollman and colleagues suggested that the mechanism of endothelium growth stimulation might be the action of substances produced by neighbouring epithelial cells. Subsequently, Goodman \& Rone (1987) showed that follicular cells in vitro release into the conditioned medium a growth factor that causes endothelial cell growth and migration, and that this was a heparin-binding protein.

The thyroid is an excellent model for understanding co-ordinated angiogenesis, because during goitre formation there is growth of follicular and endothelial cells, and it is probable that this is regulated by the release from follicular cells of cytokines in response to low concentrations of tri-iodothyronine and high concentrations of thyroid-stimulating hormone (TSH). Numerous factors have been identified that modulate angiogenesis; these include both promoters and inhibitors, which interact to control organised development of the new blood vessels. 
Table 1 Angiogenic growth factors

\begin{tabular}{l} 
Promotors \\
\hline Vascular endothelial growth factor \\
Fibroblast growth factor \\
Angiopoietins-1 and -2 \\
Angiogenin \\
Hepatocyte growth factor \\
Nitric oxide \\
Interleukin-8 \\
Platelet-derived growth factor \\
Placental growth factor \\
Proliferin \\
Endothelin
\end{tabular}

\section{Inhibitors}

Thrombospondin Angiostatin Endostatin
The function of some of these factors is unknown in the thyroid, although it is reasonable to speculate that many of them will play a role. These growth factors are summarised in Table 1.

\section{Vascular endothelial growth factor}

The principal specific promoter of endothelial cell growth and migration is vascular endothelial growth factor (VEGF), which is a secreted homodimeric glycoprotein of $46 \mathrm{kDa}$. It is chemoattractant and mitogenic for endothelial cells, and in vivo produces angiogenesis and increases vascular permeability (Ferrara et al. 1992). There are several different members of the VEGF family VEGF-A, -B, -C and -D (Carmeliet \& Collen 1997, Achen et al. 1998). All are transcribed from a single gene, then processed into several isoforms that have different tissue expression, but which bind to tyrosine kinase cell membrane receptors - VEGFR-1, -2 and -3 (also called Flt-1, Flk/KDR, and Flt-4 respectively). VEGFR-1 and -2 are principally expressed on endothelial cells. The predominant isoform is VEGF-A, which has four main configurations: VEGF-A ${ }^{120}$, VEGF-A $^{165}$, VEGF-A $^{189}$ and VEGF-A ${ }^{206}$. Another homologue, 46\% identical to VEGF-A, is placental growth factor (PlGF), which was identified in the placenta, but is also expressed in heart, lung and thyroid (Maglione et al. 1991, Viglietto et al. 1995, 1997). It binds to VEGFR-1 and can form heterodimers with VEGF-A. It can significantly potentiate the effect of VEGF-A in vitro and in vivo. The binding of the VEGF isoforms to the receptors is summarised in Fig. 1.

There is accumulating evidence that VEGF and its receptors are important in the thyroid in Graves' disease (Viglietto et al. 1997), thyroiditis (Klein et al. 1999), goitre (Wang et al. 1998) and cancer (Soh et al. 1996, 1997).

In vitro human thyroid follicular cells grown in culture can synthesise and secrete VEGF-A, and the basal level of mRNA expression can be increased by factors signalling

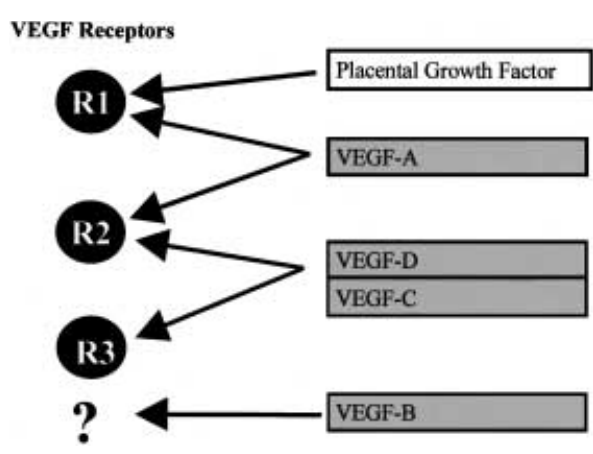

Figure 1 Binding of VEGF isoforms to the receptors.

through the cAMP and protein kinase C pathways, including TSH, dibutyryl cAMP and Graves' disease serum (Sato et al. 1995). In vivo, using a model of induced goitre in thiouracil-fed rats, VEGFR-1 and -2 mRNA expression increases during goitre formation, and this occurs subsequent to the increase in plasma TSH, and in parallel with thyroid capillary proliferation. In Graves' disease there is enhanced expression of mRNA of PlGF and VEGF in addition to VEGFR-1 and -2 (Viglietto et al. 1997) as measured by northern blot hybridisation. There is also an increased serum VEGF concentration compared with that in healthy individuals and, using colour flow Doppler ultrasonography, there is a significant correlation between serum VEGF concentration and the ratio of intrathyoidal vascular area to thyroid area, in a subgroup of patients with Graves' disease and goitre. This increased vascularity, in addition to the serum VEGF concentration, was reduced after treatment with antithyroid drugs (litaka et al. 1998).

VEGF also seems to be important in thyroid tumours. Thyroid cancer cell lines in culture secrete more VEGF than normal thyrocytes, and in these cell lines TSH increases the secretion of VEGF measured by ELISA (Soh et al. 1996, 1997). Interestingly, in a cell line derived from Hürthle cell cancer (XTC-1) there was high basal secretion of VEGF that was not increased by TSH, suggesting that VEGF secretion may be constitutively activated in some thyroid cancers (Soh et al. 1997). The expression of VEGF in vitro has been shown to correlate with in vivo aggressiveness of the tumours (Viglietto et al. 1995), with anaplastic tumours having the greatest level of expression of VEGF. Constitutively overexpressing the VEGF gene in a thyroid tumour cell line does not alter in vitro growth, but increases vascularity and reduces tumour latency when the tumour cell line is injected subcutaneously in nude mice (Belletti et al. 1999). Immunostaining of thyroid tumours shows co-localisation of increased Ki67 and VEGF staining, and this may be because areas of tumour with rapid cell division are increasing VEGF secretion to promote angiogenesis (Klein et al. 1999). The same study also showed greater 
immunostaining for VEGF in tumours that had metastasised, compared with those that had not.

It is clear that VEGF is produced by follicular cells probably in response to TSH, among other signals - and that this cytokine exerts effects on intrathyroidal endothelial cells via the VEGFR-1 and -2. VEGF receptors have not been identified on the follicular cells, although there is an intriguing report that the VEGFR-1 mRNA has been found by RT-PCR in Fisher rat thyroid (FRTL-5) cells (Wang et al. 1998); it is also not known if VEGF has an autocrine effect on follicular cells. VEGF seems to be a significant component of the regulation of angiogenesis within the thyroid and alteration in intrathyroid expression of VEGF is seen in many thyroid pathologies.

\section{Fibroblast growth factor (FGF)}

The FGF gene family consists of 13 members, which are produced by a wide range of cell types (for review see Bikfalvi et al. 1997). FGF-1 (acidic) and FGF-2 (basic) are unusual, as they lack a signal peptide necessary for the classical secretary pathway. They have high affinity for heparan sulphate glycosaminoglycans in the extracellular matrix and, although the mechanism of FGF release is not understood, there are significant amounts of FGF associated with the extracellular matrix. FGF-2 has many functions, including proliferation and chemotaxis of several cell types, including fibroblasts, endothelial cells and smooth muscle cells (Baird \& Bohlen 1990), and it is a potent stimulator of angiogenesis. Another mechanism whereby FGF may regulate angiogenesis is the secretion of binding proteins into the extracellular matrix. These binding proteins bind to and displace FGF from their bonds to heparan sulphate proteoglycans, and the displaced and soluble FGF-2 molecules can bind to receptors, initiating biological effects (Czubayko et al. 1997).

Human follicular cells express both FGF-1 and -2 in addition to the receptor FGFR-1, and expression of these factors is increased in multinodular goitre (Thompson et al. 1998). Moreover, FGF-1 is expressed by pig and sheep thyroid cells in culture, and is a potent goitrogen in rats, increasing thyroid weight by $43 \%$ after 6 days of treatment (Bidey et al. 1999). It is plausible that FGF alone may be acting as an angiogenic factor in the thyroid, with direct effects on both endothelial and follicular cell growth. However, in other tissues there is interdependence of FGF and VEGF. FGF-2 induces the expression of VEGF by endothelial cells, and the mitogenic effects of FGF-2 on endothelial cells can be blocked with anti-VEGF antibodies in vitro and in vivo (Seghezzi et al. 1998). Conversely, VEGF increases the mitogenic effects of FGF-2 on vascular smooth muscle cells in a model of rat carotid arteries injured by balloon inflation (Couper et al. 1997). It appears that there are complex relationships in the regu- lation of VEGF and FGF, and accordingly it is likely that there are interactions between the two cytokines within the thyroid, although it requires further investigation to confirm this in goitrogenesis.

\section{Matrix metalloproteinases (MMPs)}

Degradation of the extracellular matrix is essential for the formation of new blood vessels to allow in-growth of the endothelial cells, and this requires MMPs, some of which have been identified in the thyroid. Their expression can be regulated at the transcriptional level by cytokines, including VEGF, and post-translationally by interaction with other MMPs and tissue matrix metalloproteinase inhibitors (TIMPs) (Wang \& Keiser 1998). Normal thyrocytes in culture express mRNA for MMP-2, whereas thyroid anaplastic carcinoma cell lines express MMP-1, -2 and -9 and TIMP-1, -2 and -3 mRNA in vitro (Aust et al. 1997). Interestingly, the thyroid cell type that secretes the greatest amounts of MMPs are fibroblasts, and these are stimulated by phorbol esters to increase secretion of a number of MMPs, including MMP-2 and -9 (Hofmann et al. 1998). This would concur with a previous study that found expression of MMP-2 mRNA predominantly restricted to fibroblasts in thyroid tumours (Zedenius et al. 1996). It is known neither by what signal thyroid tumours might stimulate MMP release in surrounding fibroblasts, nor the role of follicular cells in regulating MMPs.

\section{Inhibitors of angiogenesis}

Thrombospondin-1 (TSP-1) is an inhibitor of endothelial cell growth associated with the extracellular matrix. It is present in the thyroid, where it is found in the stroma, and it is secreted from the apical borders of follicular cells (Prabakaran et al. 1993). Its release is inhibited by TSH, and concentrations of stromal thrombospondin decrease after 2 weeks of goitre induction, concurrently with angiogenesis occurring (Patel et al. 1996). In human thyroid tumours there is a reduction in thrombospondin mRNA and protein, and this is greatest in follicular and undifferentiated cancer (Bunone et al. 1999). Conceivably, during thyroid growth there are reduced stromal concentrations of TSP-1, possibly in response to increased TSH, which would alter the balance of pro- and anti-angiogenic factors within the thyroid.

Angiostatin is a fragment of plasminogen with antiangiogenic properties (O'Reilly et al. 1994). It is generated by urinary-type (uPA) and tissue-type (tPA) plasminogen activator in the presence of free sulphydryl donors (Gately et al. 1997). Angiostatin potently inhibits the growth of blood vessels, and prevents growth of both primary tumours and metastases (Sim et al. 1997). Both uPA and tPA are present within the thyroid, and are increased by 
TSH in vitro (Mak et al. 1984). This could lead to an increase in angiostatin formation, which theoretically may have a role in negatively regulating blood vessel formation in response to $\mathrm{TSH}$, and limiting goitre size.

\section{Angiopoietins}

The angiopoietins are $70 \mathrm{kDa}$ secreted proteins that are essential for angiogenesis. The family consists of angiopoietins-1 (Ang-1) and -2 (Ang-2), which act via a membrane tyrosine kinase receptor, Tie-2 (Davis et al. 1996, Maisonpierre et al. 1997). Ang-1 phosphorylates Tie-2, promoting endothelial cell migration, tube formation, and the stabilisation of new capillaries. Ang-2 binds to Tie-2 with similar affinity, but does not phosphorylate the receptor; it acts as a physiological antagonist to Ang-1. The function of Ang-2, however, seems to be more than simply opposing Ang-1, and it seems to regulate the response of endothelial cells to other angiogenic stimuli. To date there has been a single report that there is increased mRNA for Ang-2 and Tie-2 in thyroid neoplasia measured with RT-PCR, and this association is particularly strongly related to tumour size and progression from a pre-vascular to a vascular phase (Bunone et al. 1999).

\section{Vasoactive compounds}

Endothelin-1 (ET-1) is a potent vasoactive peptide that modulates vasomotor tone and endothelial cell proliferation. ET-1 and its receptors, ETs-A and -B, are expressed in the thyroid and increased during goitre formation (Colin et al. 1995). ET-1 may increase angiogenesis directly or via VEGF, as ET-1 can stimulate VEGF production (Pedram et al. 1997). Alternatively, the vasoactive actions of ET-1 may directly contribute to the alterations in thyroid blood flow seen in disease. Nitric oxide (NO) is another potent vasoactive compound synthesised by NO synthase (NOS) enzymes in the thyroid that also may have angiogenic functions. The vascular expansion during experimental goitre formation is reduced by antagonists of NOS, although total goitre size is not affected (Colin et al. 1995). The relationships of these vasoactive compounds to overall regulation of blood vessel growth has not been fully elucidated.

\section{Future research objectives}

The relative contribution of the different angiogenic factors within the thyroid remains to be established, especially their relationship with thyroid disease. Before treatments exploiting angiogenic strategies are used, it would be relevant to determine whether the most im- portant signal for angiogenesis in the thyroid is the removal of anti-angiogenic factors such as thrombospondin, or the expression of pro-angiogenic cytokines such as VEGF. It may then be possible to modify the angiogenic climate within the thyroid to prevent goitre or tumours.

\section{Summary}

There are many positive and negative regulators of angiogenesis, and a plethora of new cytokines have recently been identified and implicated in the regulation of blood vessel growth. However, on current understanding, VEGF is a central factor in angiogenesis in the thyroid gland, as indicated by the alterations in VEGF concentrations in many pathological conditions of the thyroid. Many other factors are involved, although some of these may act through regulation of VEGF expression in follicular cells. TSH is an important regulator of VEGF, although the role of factors important in other tissues, such as hypoxia, is not known in the thyroid. The thyroid is an excellent model for the integrated control of angiogenesis, because of the vascularity of the thyroid gland, and its capacity to increase its blood flow in disease. Further understanding of these processes may allow clinical treatments for thyroid disease, including goitre and cancer.

\section{Acknowledgements}

The author is supported by the Medical Research Council and the Get-a-Head Charity, Birmingham, UK.

\section{References}

Achen M, Jeltsch M, Kukk E, Makinen T, Vitali A, Wilks A, Alitalo K \& Stacker S 1998 Vascular endothelial growth factor D (VEGF-D) is a ligand for the tyrosine kinases VEGF receptor 2 (Flk-1) and VEGF receptor 3 (Flt-4). PNAS 95 548-553.

Aust G, Hofmann A, Laue S, Rost A, Kohler T \& Scherbaum W 1997 Human thyroid carcinoma cell lines and normal thyrocytes: expression and regulation of matrix metalloproteinase- 1 and tissue matrix metalloproteinase inhibitor-1 messenger-RNA and protein. Thyroid 7 713-724.

Baird A \& Bohlen P 1990 Fibroblast growth factors. In Peptide Growth Factors and Their Receptors, pp 369. Eds M Sporn \& A Roberts. New York: Springer-Verlag.

Belletti B, Ferraro P, Arra C, Baldassarre G, Bruni P, Staibano S, De Rosa G, Salvatore G, Fusco A, Persico MG \& Viglietto G 1999 Modulation of in vivo growth of thyroid tumor-derived cell lines by sense and antisense vascular endothelial growth factor gene. Oncogene 18 4860-4869.

Bidey SP, Hill DJ \& Eggo MC 1999 Growth factors and goitrogenesis. Journal of Endocrinology 160 321-332.

Bikfalvi A, Klein G, Pintucci G \& Rifkin D 1997 Biological roles of fibroblast growth factor-2. Endocrinological Review 18 26-45.

Bunone G, Vigneri P, Mariani L, Butó S, Collini P, Pilotti S, Pierotti MA \& Bongarzone I 1999 Expression of angiogenesis stimulators 
and inhibitors in human thyroid tumors and correlation with clinical pathological features. American Journal of Pathology 155 1967-1976.

Carmeliet P \& Collen D 1997 Molecular analysis of blood vessel formation and disease. American Journal of Physiology 273 H2091-H2104.

Colin IM, Nava E, Toussaint D, Maiter DM, Van Denhove M-F, Luscher TF, Ketelslegers J-M, Denef J-F \& Jameson JL 1995 Expression of nitric oxide synthase isoforms in the thyroid gland: evidence for a role of nitric oxide in vascular control during goiter formation. Endocrinology 136 5283-5290.

Couper LL, Bryant SR, Eldrup-Jorgensen J, Bredenberg CE \& Lindner V 1997 Vascular endothelial growth factor increases the mitogenic response to fibroblast growth factor-2 in vascular smooth muscle cells in vivo via expression of fms-like tyrosine kinase-1. Circulation Research 81 932-939.

Czubayko F, Liaudet-Coopman E, Aigner A, Tuveson A, Berchem G \& Wellstein A 1997 A secreted FGF-binding protein can serve as the angiogenic switch in human cancer. Nature Medicine $\mathbf{3}$ 1137-1140.

Davis S, Aldrich TH, Jones PF, Acheson A, Compton DL, Jain V, Ryan TE, Bruno J, Radziejewski C, Maisonpierre PC \& Yancopoulos GD 1996 Isolation of angiopoietin-1, a ligand for the TIE2 receptor, by secretion-trap expression cloning. Cell 87 1161-1169.

Denef J, Haumont S, Cornette C \& Beckers C 1981 Correlated functional and morphometric study of thyroid hyperplasia induced by iodine deficiency. Endocrinology 108 2352-2358.

Ferrara N, Houck K, Jakeman L \& Leung D 1992 Molecular and biological properties of the vascular endothelial growth factor family of proteins. Endocrine Reviews 13 18-32.

Folkman J 1971 Tumour angiogenesis: therapeutic implications. New England Journal of Medicine 285 1182-1186.

Folkman J 1995 Angiogenesis in cancer, vascular, rheumatoid and other disease. Nature Medicine 1 27-31.

Gately S, Twardowski P, Stack M, Cundiff D, Grella D, Castellino F, Enghild J, Kwaan H, Lee F, Kramer R, Volpert O, Bouck N \& Soff G 1997 The mechanism of cancer-mediated conversion of plasminogen to the angiogenesis inhibitor angiostatin. PNAS 94 10868-10872.

Goodman AL \& Rone JD 1987 Thyroid angiogenesis: endotheliotropic chemoattractant activity from rat thyroid cells in culture. Endocrinology 121 2131-2140.

Henry T 1999 Therapeutic angiogenesis. British Medical Journal 318 1536-1539.

Hofmann A, Laue S, Rost A-K, Scherbaum W \& Aust G 1998 mRNA levels of membrane-type 1 matrix metalloproteinase (MT1-MMP), MMP-2 and MMP-9 and of their inhibitors TIMP-2 and TIMP-3 in normal thyrocytes and thyroid carcinoma cell lines. Thyroid 8 203-214.

Iitaka M, Miura S, Yamanaka K, Kawasaki S, Kitahama S, Kawakami Y, Kakinuma S, Oosuga I, Wada S \& Katayama S 1998 Increased serum vascular endothelial growth factor levels and intrathyroidal vascular area in patients with Graves' disease and Hashimoto's thyroiditis. Journal of Clinical Endocrinology and Metabolism $\mathbf{8 3}$ 3908-3912.

Ishiwata T, Ino Y, Takei H, Oyama T \& Morishita Y 1998 Tumor angiogenesis as an independent prognostic indicator in human papillary thyroid carcinoma. Oncology Reports 5 1343-1348.

Klein M, Picard E, Vignaud JM, Marie B, Bresler L, Toussaint, Weryha G, Duprez A \& Leclere J 1999 Vascular endothelial growth factor gene and protein: strong expression in thyroiditis and thyroid carcinoma. Journal of Endocrinology 161 41-49.

Maglione D, Guerriero V, Viglietto G, Delli Bovi P \& Persico M 1991 Isolation of a human placenta cDNA coding for a protein related to the vascular permeability factor. PNAS $\mathbf{8 8}$ 9267-9271.

Maisonpierre PC, Suri C, Jones PF, Bartunkova S, Wiegand SJ, Radziejewski C, Compton D, McClain J, Aldrich TH,
Papadopoulos N, Daly TJ, Davis S, Sato TN \& Yancopoulos GD 1997 Angiopoietin-2, a natural antagonist for Tie2 that disrupts in vivo angiogenesis. Science 277 55-60.

Mak W, Eggo M \& Burrow G 1984 Thyrotropin regulation of plasminogen activator activity in primary cultures of ovine thyroid cells. Biochemical and Biophysical Research Communications 123 633-640.

Many M, Denef J \& Haumont S 1984 Precocity of the endothelial proliferation during a course of rapid goitrogenesis. Acta Endocrinologica 105 487-491.

O'Reilly M, Holmgren L, Shing Y, Chen C, Rosenthal R, Moses M, Lane W, Cao Y, Sage E \& Folkman J 1994 Angiostatin: a novel angiogenesis inhibitor that mediates the suppression of metastases by a Lewis lung carcinoma. Cell 79 315-328.

Patel VA, Hill DJ, Eggo MC, Sheppard MC, Becks GP \& Logan A 1996 Changes in the immunohistochemical localisation of fibroblast growth factor- 2 , transforming growth factor- $\beta 1$ and thrombospondin-1 are associated with early angiogenic events in the hyperplastic rat thyroid. Journal of Endocrinology 148 485-499.

Pedram A, Razandi M, Hu R-M \& Levin E 1997 Vasoactive peptides modulate vascular endothelial cell growth factor production and endothelial cell proliferation and invasion. Journal of Biological Chemistry 272 17097-17103.

Prabakaran D, Kim P, Kim K \& Arvan P 1993 Polarized secretion of thrombospondin is opposite to thyroglobulin in thyroid epithelial cells. Journal of Biological Chemistry 268 9041-9048.

Risau W 1997 Mechanisms of angiogenesis. Nature 386 671-674.

Sato K, Yamazaki K, Shizume K, Kanaji Y, Obara T, Ohsumi K, Demura H, Yamaguchi S \& Shibuya M 1995 Stimulation by thyroid-stimulating hormone and Graves' immunoglobulin G of vascular endothelial growth factor mRNA expression in human thyroid follicles in vitro and flt mRNA expression in the rat thyroid in vivo. Journal of Clinical Investigation 96 1295-1302.

Segal K, Shpitzer T, Feinmesser M, Stern Y \& Feinmesser R 1996 Angiogenesis in follicular tumors of the thyroid. Journal of Surgical Oncology 63 95-98.

Seghezzi G, Patel S, Ren C, Gualandris A, Pintucci G, Robbins E, Shapiro R, Galloway A, Rifkin D \& Mignatti P 1998 Fibroblast growth factor-2 (FGF-2) induces vascular endothelial growth factor (VEGF) expression in the endothelial cells of forming capillaries: an autocrine mechanism contributing to angiogenesis. Journal of Cell Biology 141 1659-1673.

Sim K, O'Reilly M, Liang H, Fortier A, He W, Madsen J, Lapcevich R \& Nacy C 1997 Recombinant human angiostatin protein inhibits experimental primary and metastatic cancer. Cancer Research $\mathbf{5 7}$ 1329-1334.

Smeds S \& Wollman S $1983{ }^{3} \mathrm{H}$-Thymidine labeling of endothelial cells in thyroid arteries, veins and lymphatics during thyroid stimulation. Laboratory Investigation 48 285-291.

Soh EY, Sobhi SA, Wong MG, Meng YG, Siperstein AE, Clark OH \& Duh QY 1996 Thyroid-stimulating hormone promotes the secretion of vascular endothelial growth factor in thyroid cancer cell lines. Surgery 120 944-947.

Soh E, Duh Q, Sobhi S, Young D, Epstein H, Wong M, Garcia Y, Min Y, Grossman R, Siperstein A \& Clark O 1997 Vascular endothelial growth factor expression is higher in differentiated thyroid cancer than in normal or benign thyroid. Journal of Clinical Endocrinology and Metabolism 82 3741-3747.

Thompson SD, Franklyn JA, Watkinson JC, Verhaeg JM, Sheppard MC \& Eggo MC 1998 Fibroblast growth factors 1 and 2 and fibroblast growth factor receptor 1 are elevated in thyroid hyperplasia. Journal of Clinical Endocrinology and Metabolism $\mathbf{8 3}$ 1336-1341.

Viglietto G, Maglione D, Rambaldi M, Cerutti J, Romano A, Trapasso F, Fedele M, Ippolito P, Chiapetta G, Botti G, Fusco A \& Persico MG 1995 Upregulation of vascular endothelial growth 
factor (VEGF) and down-regulation of placenta growth factor (PlGF) associated with malignancy in human thyroid tumors and cell lines. Oncogene 11 1569-1579.

Viglietto G, Romano A, Manzo G, Chiappetta G, Paoletti I, Califano D, Galati MG, Mauriello V, Bruni P, Lago CT, Fusco A \& Persico MG 1997 Upregulation of the angiogenic factors PlGF, VEGF and their receptors (Flt-1, Flk-1/KDR) by TSH in cultured thyrocytes and in the thyroid gland of thiouracil-fed rats suggest a TSHdependent paracrine mechanism for goiter hypervascularization. Oncogene 15 2687-2698.

Wang H \& Keiser J 1998 Vascular endothelial growth factor upregulates the expression of matrix metalloproteinases in vascular smooth muscle cells: the role of flt-1. Circulation Research 83 832-840.

Wang JF, Milosveski V, Schramek C, Fong GH, Becks GP \& Hill DJ 1998 Presence and possible role of vascular endothelial growth factor in thyroid cell growth and function. Journal of Endocrinology $1575-12$.

Wollman S, Herveg J, Zeligs J \& Ericson L 1978 Blood capillary enlargement during the development of thyroid hyperplasia in the rat. Endocrinology 103 2306-2312.

Zedenius J, Stahle-Backdahl M, Enberg U, Grimelius L, Larsson C, Wallin G \& Backdahl M 1996 Stromal fibroblasts adjacent to invasive thyroid tumors: expression of gelatinase A but not stromelysin 3 mRNA. World Journal of Surgery 20 101-106.

Received 20 December 1999

Revised manuscript received 14 April 2000 Accepted 11 May 2000 